\title{
Portrayal of organ donation and transplantation on American primetime television
}

Harbaugh C, Afana M, Burdick S, East J, Kodali S, Lee J, Patel S, Rangrass G, Ranney D, Sood V, Lynch R, Sonnenday CJ, Englesbe MJ, Mathur AK. Portrayal of organ donation and transplantation on American primetime television.

Clin Transplant 2011: 25: E375-E380. @ 2011 John Wiley \& Sons A/S.

Abstract: Recently, both living and deceased organ donation rates have hit a plateau, despite increases in need for viable organs. One approach to improve donation rate is public education and policy; thus, it is necessary to understand the information the public is receiving regarding organ donation. We hypothesized that primetime medical dramas portray organ donation and transplantation in a negative manner. We compiled data on all primetime medical drama episodes with transplant themes from November 2008 through June 2010 and assessed depictions of organ donors and transplant candidates. Positive and negative thematic elements surrounding the process and individuals involved were also identified. One hundred and fifty-five million and 145 million households watched episodes containing any negative message and any positive message, respectively. Episodes containing only negative messages had over twice the household viewership per episode compared to episodes containing only positive messages ( 8.4 million vs. 4.1 million, $\mathrm{p}=0.01$ ). Widespread exposure to these representations may reinforce public misconceptions of transplantation. The transplant community should consider the popularity of medical dramas as an opportunity to impact the perception of organ donation and transplantation for millions of Americans.

\author{
Calista Harbaugh, Majed Afana, \\ Stephanie Burdick, Joseph East, \\ Sindhura Kodali, Jay Lee, Shaun \\ Patel, Govind Rangrass, David \\ Ranney, Vikram Sood, Raymond \\ Lynch, Christopher J. Sonnenday, \\ Michael J. Englesbe and Amit K. \\ Mathur
}

Summer Surgery Student Research Program, Department of Surgery, University of Michigan, Ann Arbor, MI, USA

Key words: donation rates - media - organ donation - organ transplantation - public policy

Corresponding author: Michael J. Englesbe, MD, Department of Surgery, University of Michigan Medical School, 2926A Taubman Center, 1500 East Medical Center Drive, Ann Arbor, Ml 481095331, USA.

Tel.: 734936 9623; fax: 734936 5830;

e-mail: englesbe@umich.edu

Conflict of interest: None.

Accepted for publication 12 January 2011
The transplant community is well aware of the shortage of organ donors. Of particular concern are recent plateaus in deceased and living donation rates (1). Because the number of donors has not risen to meet the need for organs, it is critical that the transplant community carefully assesses public perceptions of organ transplantation and donation to improve organ donation rates. To this end, it is necessary to fully understand the sources of information that drive these public perceptions.

Television is a well-known source of medical information for the public. With the average American watching $2.8 \mathrm{~h}$ of television daily, it is conceivable that mass media has a profound impact on the public's perception of organ donation and transplantation (2-5). Medical dramas have consistently been popular for decades (6) and have focused on interesting and often controversial patient conditions and clinical scenarios. Previous work has shown that in 2004-2005, there was no positive or accurate presentation of organ donation in the popular television (2). In response, the donation and transplant community began to launch efforts to more closely engage the entertainment industry. However, little work has been performed to assess the effectiveness of these efforts, particularly in the genre of medical dramas. Considering their potential role as arbiters of knowledge regarding donation and transplantation, it is important to characterize how transplantation is represented in this genre.

We hypothesized that representations of organ donation and transplant events on primetime television in the medical drama genre would 
continue to have negative connotations. We further hypothesized that these negative representations would be reaching vast numbers of American viewers with each broadcast. To test these hypotheses, we compiled data on all primetime medical drama episodes on major commercial networks over a 19-month period. We assessed how organ donors and transplant candidates are depicted and identified positive and negative thematic elements surrounding the process of organ donation and transplantation. This work suggests that direct engagement with popular media outlets and social media may provide significant opportunities for public education.

\section{Methods}

All medical drama television shows broadcasted during primetime hours (7:00-11:00 PM EST) on four major commercial networks (ABC, NBC, FOX, CBS) from November 2008-June 2010 were considered in this study. Nine television shows fulfilled these criteria: House M.D., Grey's Anatomy, Private Practice, Scrubs, ER, Three Rivers, Mercy, Miami Medical, and Trauma. Closed caption transcripts of all episodes during the observation period were queried using specific keywords to identify episodes discussing transplantation for further review (2). The keywords included: transplant, transplantation, organ donation, organ donor, and brain death.

An instrument was developed to identify and score the primary themes of each episode (Appendix 1). These potential themes had been previously studied and validated (2). Inter-rater agreement was ensured by testing the instrument among all data abstracters and resolving discrepancies with group discussion. Following instrument validation on test episodes, television episodes were randomly divided among 10 potential reviewers. Each television episode was viewed and graded independently by two of 10 potential reviewers (Appendix 1). From each episode, data were collected on the demographics, the types of organs transplanted, conditions of donation (living related, living unrelated, donation after brain death, donation after cardiac death), demographics of potential donors and recipients, presence of social support for recipients and donors, donor motivation and willingness to donate among potential donors, and recipient indications for transplantation (3). After scoring each episode, both reviewers recorded their observations in a composite data entry field. Discrepancies between reviewers occurred in less than $5 \%$ of the episodes and were resolved through discussion. Viewership per episode was calculated based on Nielsen household television ratings and total broadcast universe, when available, or collected directly from published weekly episode viewership $(6,7)$.

Descriptive statistics were calculated for demographics, conditions of donation, and potential donor willingness and motivation. Themes were categorized according to positive, negative, or neutral portrayal $(2,3)$. Themes specifically related to developing mistrust in the medical system were indicated for further analysis. Viewership and average viewership based on theme were calculated to assess the extent to which the dominant messages were conveyed to the audience. Unpaired Student's $t$-test was used to compare average episode viewership of positive and negative themes.

\section{Results}

Descriptive statistics of included episodes are shown in Table 1. Of all primetime medical drama episodes aired between November 2008 and June $2010(\mathrm{n}=235), 49$ containing transplant-specific keywords were identified for further review. Fortyone episodes were determined relevant to organ transplant and/or donation. Transplantation drove the main plot line in $21(51.2 \%)$ of these episodes. The most common organs featured for transplantation or donation were the heart $(45.0 \%)$ or the liver $(34.1 \%)$.

Potential living donor $(\mathrm{n}=14)$, deceased donor $(\mathrm{n}=21)$, and recipient $(\mathrm{n}=46)$ demographics are shown in Table 2. Consistently among the three populations, the majority of the characters portrayed were middle-aged $(92.9 \%$ of potential living donors, $57.1 \%$ of deceased donors, $52.2 \%$ of recipients) and Caucasian $(85.7 \%$ of potential living donors, $76.2 \%$ of deceased donors, $80.4 \%$ of recipients). Deceased donors tended to be men $(90.5 \%$ men) when compared to living donors $(42.9 \%$ men $)$ and recipients $(54.4 \%$ men $)$.

Table 1. Episode characteristics

Episodes $(n=41)$

\begin{tabular}{lc}
\hline Transplant involvement & \\
Main plot & $21(51.2 \%)$ \\
Sub-plot & $12(29.3 \%)$ \\
Brief reference & $8(19.5 \%)$ \\
Organ type & \\
Heart & $18(45.0 \%)$ \\
Liver & $14(34.1 \%)$ \\
Kidney & $5(12.5 \%)$ \\
Lungs & $5(12.5 \%)$ \\
Pancreas & $0(0.0 \%)$ \\
Others & $11(27.5 \%)$ \\
\hline
\end{tabular}


Table 2. Demographics

\begin{tabular}{|c|c|c|c|}
\hline & $\begin{array}{l}\text { Deceased } \\
\text { donor }(n=21)\end{array}$ & $\begin{array}{l}\text { Living donor } \\
(n=14)\end{array}$ & $\begin{array}{l}\text { Transplant } \\
\text { candidate } \\
(n=46)\end{array}$ \\
\hline \multicolumn{4}{|l|}{ Age } \\
\hline Middle-aged adult & $12(57.1 \%)$ & $13(92.9 \%)$ & $23(52.2 \%)$ \\
\hline Young adult & $3(14.3 \%)$ & $1(7.1 \%)$ & $9(20.0 \%)$ \\
\hline Child/teen & $6(28.6 \%)$ & $0(0.0 \%)$ & $13(28.3 \%)$ \\
\hline $\begin{array}{l}\text { Gender } \\
\text { Male }\end{array}$ & 19 (90.5\%) & $6(42.9 \%)$ & $25(54.4 \%)$ \\
\hline Female & $2(9.5 \%)$ & $8(57.1 \%)$ & $21(45.7 \%)$ \\
\hline \multicolumn{4}{|l|}{ Race } \\
\hline Caucasian & 16 (76.2\%) & $12(85.7 \%)$ & $37(80.4 \%)$ \\
\hline African American & $3(14.3 \%)$ & $0(0.0 \%)$ & $5(10.9 \%)$ \\
\hline Hispanic & $0(0.0 \%)$ & $1(7.1 \%)$ & $2(4.4 \%)$ \\
\hline Other & $2(9.5 \%)$ & $1(7.1 \%)$ & $2(4.4 \%)$ \\
\hline \multicolumn{4}{|l|}{ Support network } \\
\hline Family & $18(85.7 \%)$ & $13(92.9 \%)$ & $36(78.6 \%)$ \\
\hline Friends & $1(4.8 \%)$ & $3(21.4 \%)$ & $9(19.6 \%)$ \\
\hline
\end{tabular}

Thirty-one of $46(68.9 \%)$ potential transplant recipients received the organs.

Potential donors were further characterized by conditions of donation, motivation, and willingness to donate (Fig. 1). Overall, 67\% of donors portrayed were deceased donors, including donation after brain death and cardiac death, while $33 \%$ of all donors were living, including related and unrelated. Altruism was the motivation for organ donation in $53.5 \%$ of potential donors, and family pressure to donate was the leading motivation in $9 \%$ of potential donors. Similarly, among potential donors portrayed, $67 \%$ showed willingness to donate when compared to $4 \%$ who were unwilling.

Frequencies of episodes conveying overall positive and/or negative messages are shown in Fig. 2. Six themes were categorized as conveying a positive message and 12 themes as conveying a negative message. In addition, 155 million households viewed an episode containing any negative message when compared to 145 million households that viewed episodes containing any positive message. In evaluating the average number of households viewing each episode, episodes containing only positive messages had an average household viewership of 4.1 million and episodes containing only negative messages had average household viewership of 8.4 million $(\mathrm{p}=0.01)$.

Five themes specifically addressed potentially inaccurate depictions of the medical system as related to organ donation or transplant (Fig. 3). Forty-four million households were sent the message that doctors "game" the organ donation system and 43 million households viewed an episode portraying doctors as vultures, eagerly awaiting organ procurement.

\section{Discussion}

The large viewership of the medical drama genre on American primetime television represents a significant potential source of public education regarding transplantation. In this study, we have characterized how transplantation is portrayed in this genre and determined the number of viewers exposed to specific representations of organ donation and transplantation. During the observation period, over 155 million households viewed episodes that depicted transplantation unfavorably, including 44 million households who viewed episodes that depicted doctors exerting personal influence to circumvent organ allocation policies. In addition, significantly more people viewed episodes with only negative portrayals of transplantation than those with only positive portrayals. Such widespread exposure to these representations may reinforce public misconceptions of transplantation.
Fig. 1. Both the (A) conditions of donation and (B) willingness to donate were recorded for all potential donors. The majority of potential organs were donated after brain death $(64 \%)$. Potential donors were typically willing to donate organs $(67 \%)$.
A

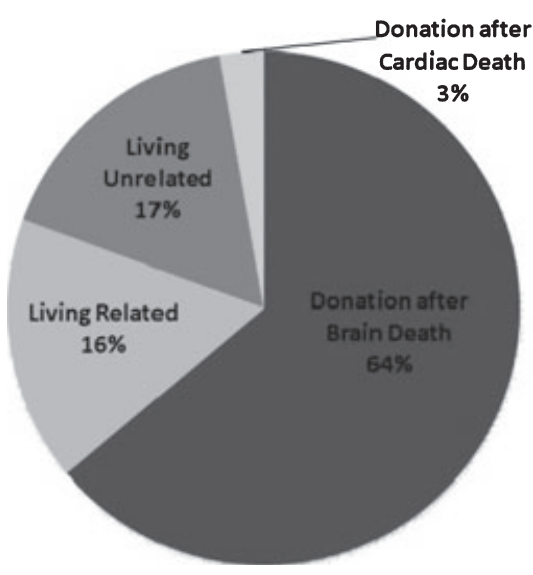

B Willingness to Donate

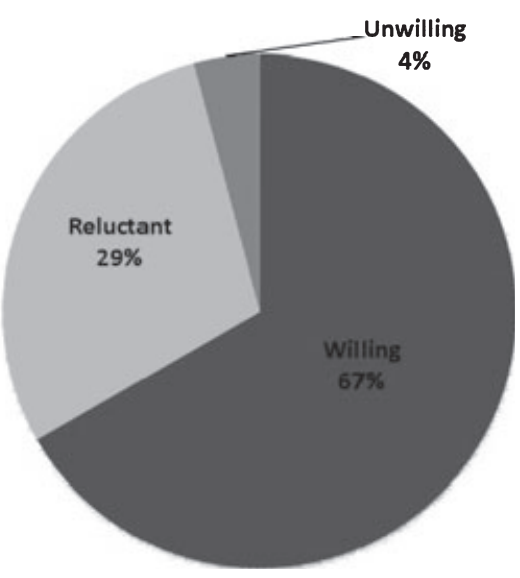




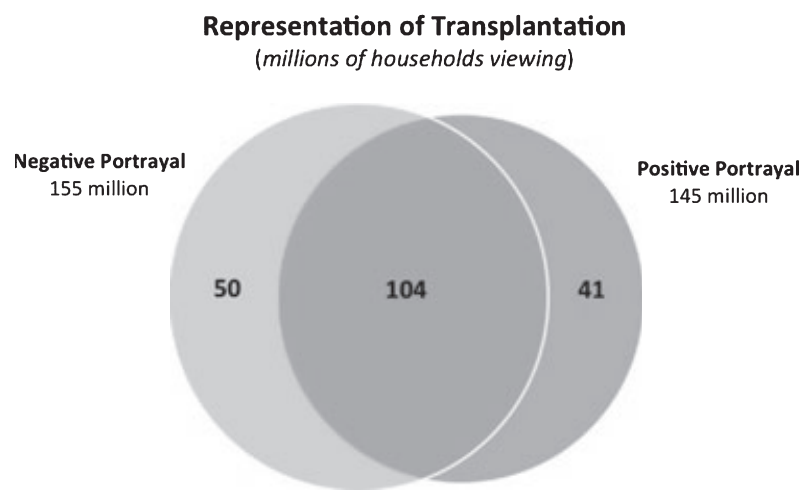

Fig. 2. Themes from each primetime medical drama episode involving organ donation and transplantation were categorized according to positive or negative portrayal and total household viewership of each category was calculated. Negative messages (155 million households) were more prominent than positive messages (145 million) in popular medical drama television.

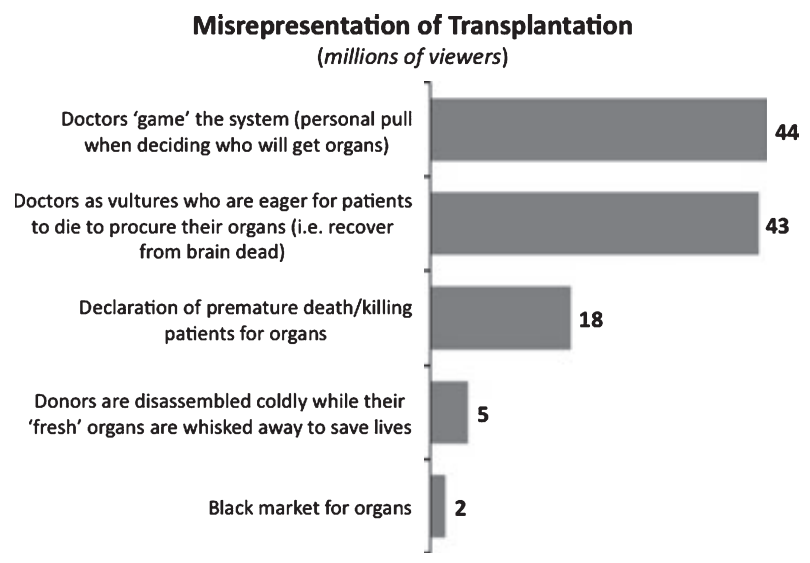

Fig. 3. Household viewership of five themes specifically emphasizing mistrust of the medical system was calculated for comparison. Number of households that viewed each theme was calculated, and some households may have seen multiple themes emphasizing mistrust in the medical system per episode.

The transplant community should strongly consider the popularity of medical dramas as an opportunity to impact the perceptions of millions of Americans regarding organ donation and transplantation.

Audiences watching primetime medical dramas clearly receive conflicting messages about organ donation. The tension between positive and negative portrayals of organ donation and transplantation correlates with similar studies performed on the portrayal of organ donation in television in the mass communications literature (2). Previous empirical studies in which subjects were shown actual episodes and then evaluated indicated that simply watching an episode with inaccurate information about organ donation led to negative opinions of donation and overall decreased sup- port of organ donation among non-donors (3, 5, 8, 9). Additional studies found that focus group discussions on organ donation reflected themes that were identified in mass media during a previous study and that viewers acquired knowledge from the content of each drama, despite the fact that some content was inaccurate $(2,10,11)$. More strikingly, viewers who were not organ donors prior to exposure were more likely to decide to donate if the drama explicitly encouraged donation by discussing its merits and by portraying characters making the decision to donate. Conversely, if an episode focused on a particular negative myth as a theme, viewers were also more likely to accept the myth as fact (12). Media messages clearly affect the formation of public opinion and may have profound influence on individual decisions regarding donation, particularly considering the high volume of viewers and the lack of alternative sources of information. People see positive representations of the process as well as favorable outcomes, but with 157 million households viewing negative themes that may establish mistrust of the medical system, it is possible that these negative connotations and themes deter individuals from making the choice to donate. Further study is necessary to determine whether these portrayals are linked to actual donor registration rates.

Television producers and cast members of medical dramas that negatively portray organ transplant are not likely aware of the potentially deleterious messages being delivered to their audiences. Analysis of more than 80 popular television episodes aired in 2004 and 2005 revealed that there were no presentations of organ donation in an accurate or positive light (2). In response, the donation and transplant community launched Donate Life Hollywood in July 2007 to more closely engage the entertainment industry (more information can be found on their website at http://www.donatelifehollywood.org/). Within this context, our work has demonstrated improvements, with nearly half of the portrayals of organ donation, transplantation, and the medical system in a positive manner; however, there is still much work to be carried out. Television producers in this genre, screenwriters, and cast members will continue to be important allies in the effort to educate the general public on organ donation. Lobbying for the alteration of the plot lines to provide more realistic representations of organ donation and transplantation would have to be pursued with great care from the transplant community, if even appropriate. Television producers of medical drama could, however, take short segments of on-air 
time to candidly state the facts regarding organ transplantation (as provided by the transplant community) while promoting their own primetime dramas, similar to media advocacy of other health issues such as breast cancer, drunk driving, and domestic violence through short, on-air monologues. Together, the collaborative effort of the transplant community and primetime media has great potential to save lives and should be pursued as an avenue to educate the public on organ transplantation and donation.

This study has important limitations that should be noted. First, our sample size with respect to both time and number of shows on television was fairly small. Our attention was specifically on medical dramas during primetime television and only on the major networks. Therefore, we did not include other possible contributors, such as those found on other networks, during other times of the day, or through other forms of media aside from television. However, television has been shown to be the major source of information about organ donation when compared to radio, press, and magazines, and so we chose this as our focus (13). Also, because of their more technical nature, use of complex medical language, and emotionally provocative storylines, we studied the genre of medical drama exclusively. Previous studies have shown that viewers are more likely to be persuaded by such narratives, leading to incorporation of the depicted messages into their own beliefs (14). Second, the method by which the themes were analyzed was subjective, though based on previous methods. In an effort to maximize inter-rater agreement, pairs of individuals independently watched and reported the themes they felt were depicted in the shows. However, there was still room for some disagreement, although this was rare. In addition, researchers with sophisticated knowledge of transplantation categorized these subjective themes, potentially introducing bias. Third, in this study, we have characterized the message portrayed to the public, rather than the message received. Because millions of Americans are watching these shows, it is simply not possible to document all of their perceptions. As a result, we could only quantify how many households watched these shows.

Considering both the shortage of organ donors and the prominence of popular television as a source of medical education for the American public, we have characterized the current portrayal of organ donation and transplantation in a popular television genre. We noted that negative portrayals of organ donation and transplantation were remarkably common and may have deleteri- ous implications on individual decisions to donate and overall perceptions of the transplantation process. We encourage the transplant community to engage the public through primetime television media and other opportunities using innovative social media, in addition to continuing current successful efforts to promote public awareness of organ donation and transplantation.

\section{Appendix}

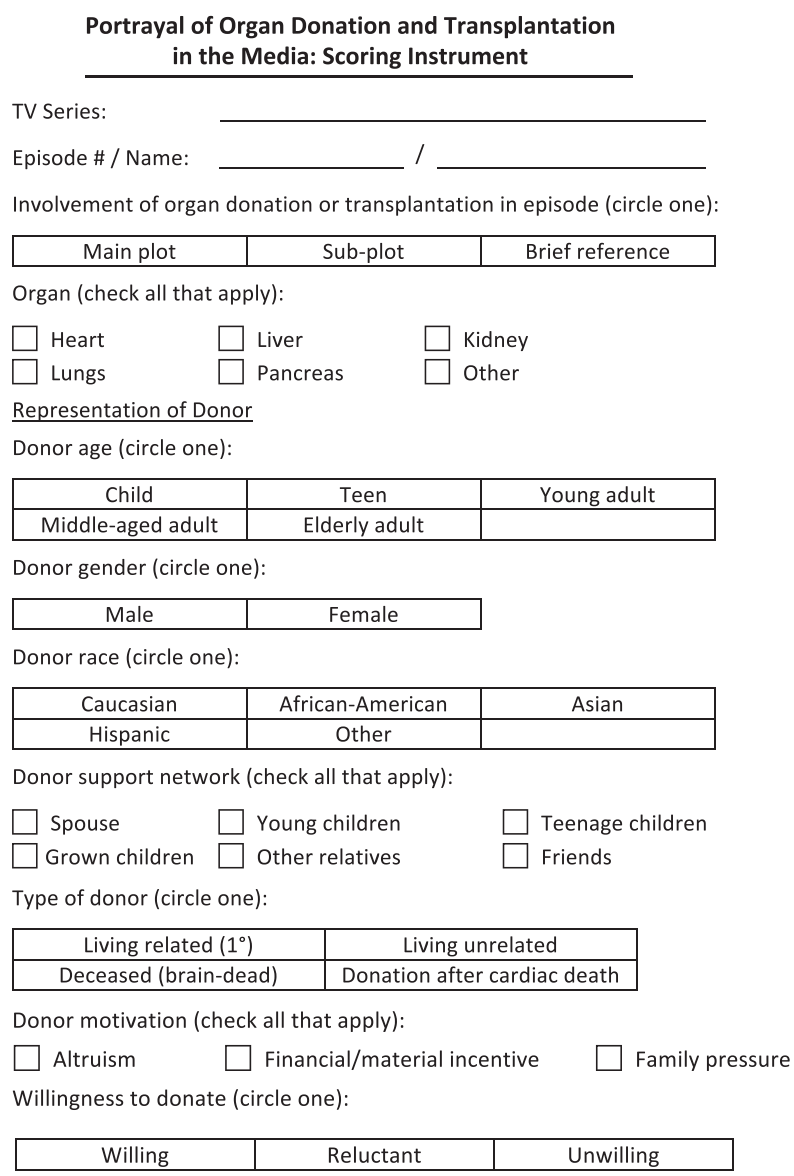

Representation of Recipient

Recipient age (circle one):

\begin{tabular}{|c|c|c|}
\hline Child & Teen & Young adult \\
\hline Middle-aged adult & Elderly adult & \\
\hline \multicolumn{3}{|c|}{ Recipient gender (circle one): } \\
\hline Male & Female & \\
\hline \multicolumn{3}{|c|}{ Recipient race (circle one): } \\
\hline Caucasian & African-American & Asian \\
\hline Hispanic & Other & \\
\hline
\end{tabular}

Recipient support network (check all that apply):

$\square$ Spouse $\square$ Young children
$\square$ Grown children $\square$ Other relatives
Reason for needing transplant:
Was organ received (circle one)?
\begin{tabular}{|c|l}
\hline Yes & No \\
\hline
\end{tabular}

Teenage children Friends 


\section{Harbaugh et al.}

\section{Episode Themes (check all that apply)}

Multiple potential donors available

Cultural or religious beliefs in contradiction to organ donation or transplantation

Tragic outcome (i.e. not getting an organ, organ failure)

Family problems resulting from donation

Family problems resulting from needing or getting an organ

Reuniting the family

Recipients and/or their family members secretly hope for the death of another person so they can have their organs

$\square$ Undeserving or ungrateful recipients, including alcoholics, prisoners, abusers, and other 'bad' people

Organ donors are good people

General positive representation of recipient (nothing 'special')

'Much loved' recipient (male or female) - usually shown with concerned extended family and/or friends who are grateful the recipient received the transplant

Black market for organs

Doctors 'game' the system (personal pull when deciding who will get organs)

Declaration of premature death/killing patients for organs

Doctors as vultures who are eager for patients to die to procure their organs (i.e. recover from brain dead)

Rich people can buy anything, including life or life of others

$\square$ Donors are disassembled coldly while their 'fresh' organs are whisked away to save lives

Positive portrayal of physicians

Positive portrayal of nurses and/or support staff

Conflict among medical staff

Effort to correct misinformation once presented in the episode

Additional theme not listed:

\section{References}

1. OPTN data on Donors Recovered in the U.S. by Donor Type: http://optn.transplant.hrsa.gov/latestData/rptData. asp; accessed July 27, 2010.

2. Morgan SE, Harrison TR, Chewning L, Davis L, DiCORCIA M. Entertainment (mis)education: the framing of organ donation in entertainment television. Health Commun 2007: 22: 143 .
3. Morgan SE, Harrison TR, Long SD, Afifi WA, StePhenson MT, ReICHERT T. Family discussions about organ donation: how the media influences opinions about donation decisions. Clin Transplant 2005: 19: 674.

4. Morgan SE, Miller JK. Beyond the organ donor card: the effect of knowledge, attitudes, and values on willingness to communicate about organ donation to family members. Health Commun 2002: 14: 121.

5. Morgan SE, Stephenson MT, Harrison TR, Afifi WA, LONG SD. Facts versus 'feelings': how rational is the decision to become an organ donor? J Health Psychol 2008: 13: 644 .

6. TV by the Numbers. http://tvbythenumbers.com/category/ ratings/tv-ratings-nielsen-overnight-tv-show-ratings; accessed July $27,2010$.

7. The Nielsen Ratings. http://blog.nielsen.com/nielsenwire/ wp-content/uploads/2009/08/2009-2010-dma-ranks.pdf; accessed July 27, 2010.

8. Harrison TR, Morgan SE, Chewning LV. The challenges of social marketing of organ donation: news and entertainment coverage of donation and transplantation. Health Mark Q 2008: 25: 33.

9. Harrison TR, Morgan SE, Di Corcia MJ. Effects of information, education, and communication training about organ donation for gatekeepers: clerks at the Department of Motor Vehicles and organ donor registries. Prog Transplant 2008: 18: 301.

10. Maloney G, Walker I. Talking about transplants: social representations and the dialectical, dilemmatic nature of organ donation and transplantation. $\mathrm{Br} \mathbf{J}$ Soc Psychol 2002: 41: 299.

11. Maloney G, Walker I. Messiahs, pariahs, and donors: the development of social representations of organ transplants. J Theory Soc Behav 2000: 30: 203.

12. Morgan S, Movius L, Cody M. The power of narratives; the effect of entertainment television organ donation storylines on the attitudes, knowledge and behaviors of donors and nondonors. J Commun 2009: 59: 135 .

13. Conesa C, Rios Zambudio A, Ramirez P, Canteras M, Rodriguez MM, PARrilla P. Influence of different sources of information on attitude toward organ donation: a factor analysis. Transplant Proc 2004: 36: 1245.

14. GREen M. Transportation into narrative worlds: the role of prior knowledge and perceived realism. Discourse Process 2004: 38: 247. 